\title{
Epidemiology of multiple sclerosis in the counties of Northumberland and Durham
}

\author{
DAVID C. POSKANZER ${ }^{1}$, KURT SCHAPIRA ${ }^{2}$, AND \\ HENRY MILLER
}

\begin{abstract}
From the Department of Neurology, the Royal Victoria Infirmary, and the Medical Research Council Research Group on Demyelinating Diseases, Newcastle upon Tyne
\end{abstract}

Considerable variations in the scope and the methods of ascertainment employed in different epidemiological studies, to say nothing of divergent diagnostic criteria, have seriously jeopardized the value of many such observations in estimating the true prevalence of multiple sclerosis in various parts of the world.

Acheson has pointed out that studies based on mortality statistics (Limburg, 1950; Acheson, 1961) are subject to misreporting and under-reporting which reduce their accuracy and comparability. Studies of hospital records (Chiavacci, Hoff, and Polvan, 1950), augmented on occasion by interviews of practising physicians and examination of death certificates (Ipsen, 1950), represent further attempts to obtain more accurate data. Investigations of special population groups such as U.S. veterans (Acheson and Bachrach, 1960; Acheson, Bachrach, and Wright, 1960), for which comprehensive medical records are available, have afforded opportunities for more circumscribed studies.

However, the personally conducted population survey, drawing on every available source to compile a comprehensive register of patients, has been recognized as a superior method. Essential to the survey is the establishment of firm diagnostic criteria, which not only lend reliability to the investigation but also permit the subsequent employment of data in authentic comparative studies. One such survey in the field of multiple sclerosis was published more than 30 years ago (Allison, 1931) and important contributions on similar lines have been made by MacLean, Berkson, Woltman, and Schionneman (1950), Allison and Millar (1954), Hyllested (1956), Sutherland (1956), and Alter, Allison, Talbert, and Kurland (1960). These observations furnish a valuable frame of reference for studies now under way in several other parts of the world.

1 Of the Department of Epidemiology, Harvard School of Public Health, and Department of Neurology, Massachusetts General Hospital. Formerly Moseley Travelling Fellow of Harvard University.

${ }^{2}$ This work was based in part on a thesis for the degree of Doctor of Medicine in the University of Durham.
The present investigation was undertaken to study the epidemiological features of multiple sclerosis in Northumberland and Durham, comprising a comparatively stable population of over two million people of relatively uniform racial stock. This population is served by two neurologists based on the Medical School in Newcastle upon Tyne. Over the past 30 years only three individual and closely associated consultant neurologists have furnished this service, ensuring a uniformity in diagnostic standards, the lack of which has ofteno presented one of the major difficulties in studies of this kind.

Northumberland is the most northerly English county, bounded by Durham to the south and westwards by Cumberland (see Fig. 1). It comprises an area of over 2,000 square miles with a population of 811,400 (1958 census estimate), a large proportiof of which is employed in mining and shipbuilding in the small but thickly peopled south-eastern part of the county. Durham is a more densely populated county with a population of $1,497,000$ (1958 census estimate) occupying an area of approximately 970 square miles. Its economy is mainly dependent on heavy industry, a third of those employed being engaged in mining, quarrying, or shipbuilding.

\section{METHODS}

CASE COLLECTION Letters were sent to all general practitioners in the two counties requesting a report on all cases of multiple sclerosis in their practices. Most of these practitioners were working in the framework of the National Health Service but the small group engaged entirely in private practice was also included. Practitioners who failed to reply were circulated a second time. Those outstanding after the second letter were then offered a modest financial inducement to report: on this occasion most replied, almost invariably waiving the fee. The National Health Service lists of those replying comprised $92.5 \%$ of the estimated population of the two counties. The data concerning the response are summarized in Table I. Although $11.4 \%$ of the practices were not 


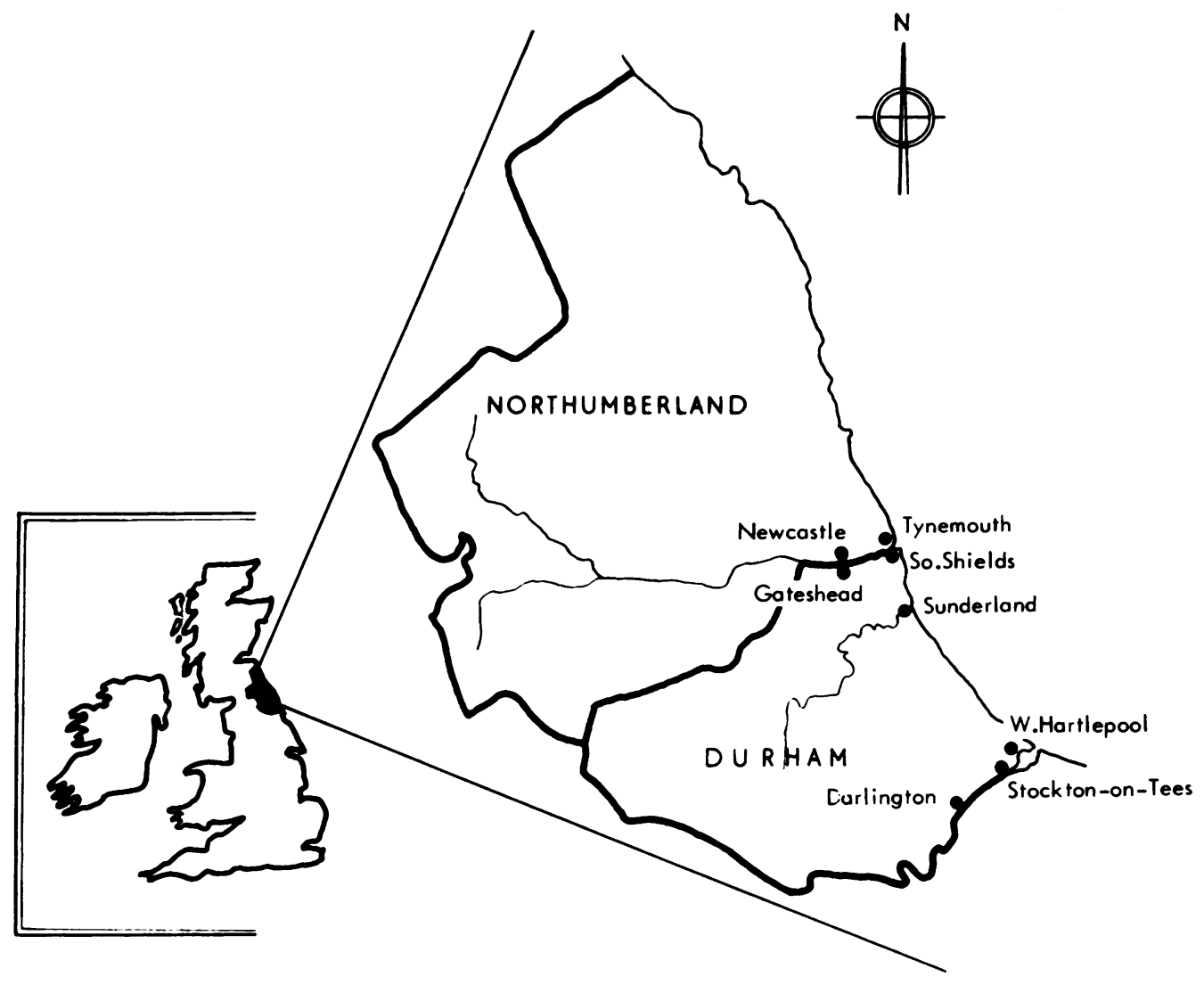

FIG. 1. Counties of Northumberland and Durham showing cities with a population of 50,000 or greater.

TABLE I

RESPONSE OF GENERAL PRACTITIONERS TO REQUEST FOR REPORTING OF PATIENTS WITH MULTIPLE SCLEROSIS

Northumberland

Durham

Total

General practitioners reporting

Practices reporting

366
199
$11 \cdot 6$
410
752,111
811,400

Percentage practices not reporting

Cases reported as multiple sclerosis

Total patients in practices

Census estimate of population

Percentage population represented by doctors' reports

$11 \cdot 6$

52,111

$92 \cdot 7$

481
277

$11 \cdot 2$

604

$1,383,213$

$1,497,000$

$92 \cdot 4$

847
476
$11 \cdot 4$
$1,014^{1}$
$2,135,324$
$2,308,400$
$92 \cdot 5$

${ }^{1}$ Of this group 260 patients were not suffering from multiple sclerosis, had onset after 1 January 1958 , or resided outside the counties of Northumberland and Durham. 
reported, they represented only $7.5 \%$ of the population, presumably because some physicians who failed to report were no longer in practice, had left the area, or had small practices. The reporting was remarkably similar in the two counties. Of the 1,014 cases reported by practitioners, 260 were eliminated because they were found later not to be suffering from multiple sclerosis, or because they resided outside the counties of Northumberland or Durham or the onset was after prevalence day (1 January 1958). The first 700 cases reported (group A) were investigated intensively by clinical examination and an extended anamnesis for use as a base-line population in clinical trials. From group A, 636 cases were retained for the study. From the remaining cases reported by practitioners 118 additional patients, hereafter referred to as group B, were investigated only to establish diagnosis and to obtain essential epidemiological information.

While information was sought on cases reported by general practitioners, a team of house physicians and final-year medical students searched the records of each hospital in the region for patients with multiple sclerosis residing in Northumberland or Durham on 1 January 1958. Records of patients who had not been seen by one of the neurologists were investigated further. Hospital records were searched from the establishment of the National Health Service in 1948 until 1960. The majority of these cases came from the records of the two neurologists at the Royal Victoria Infirmary and the Newcastle General Hospital, which are associated with the Medical School in Newcastle. Twenty-seven other hospitals in the two counties were also visited and their records searched. When the last admission to hospital had taken place before 1 January 1958, or where data were incomplete in the hospital record, a letter and questionnaire were sent to the patient or if he was inaccessible to his practitioner, who was traced through the National Health Service registration records. In this way, 402 additional cases of multiple sclerosis were located (group C).

The cooperation of the Registrar General enabled us to exclude patients who had died before 1 January 1958. Data referring to all three groups were entered on machine cards and tabulated. When questions of diagnosis or duplication arose, the patients were re-examined at hospital or in their homes, or information was sought from their practitioners. If they were still living in the area, patients who had not already been diagnosed as having multiple sclerosis by one of the three regional neurologists were re-examined.

DIAGNOSIS It must be admitted at once that the lack of any valid laboratory test puts a heavy premium on clinical skill and experience in the diagnosis of multiple sclerosis. The highest attainable reliability of diagnosis is clearly a prerequisite for the study of any aspect of the disease. In this context the hereditary ataxias and paraplegias constitute well-recognized pitfalls. The symptoms of neurofibroma, meningioma, and angioma may be wrongly attributed to a demyelinating disease, and the recognition of intermittent insufficiency in the vertebrobasilar circulation presents a more recently appreciated hazard. In this study we have therefore adopted the classical criterion of "evidence of dissemination of lesions in time and space.' The patients were designated $\bar{Z}$ as cases of 'probable' multiple sclerosis when they $\stackrel{\mathbb{D}}{=}$ unequivocally satisfied these clinical criteria and when there was little reasonable doubt about the diagnosis. Neither was there much doubt in cases classified as $\hat{\theta}$ 'latent' multiple sclerosis. Although these patients were $\mathcal{D}$ asymptomatic at the time of examination, they gave a characteristic history of episodic multifocal neurological $\stackrel{\rho}{\subseteq}$. disease which defied alternative explanation. The term 'possible' multiple sclerosis was applied in cases where. alternative diagnoses had been excluded as far as practic- $\overrightarrow{\vec{F}}$ able and where the clinical picture was more suggestive $\stackrel{?}{+}$ of multiple sclerosis than of any other recognizable neurological disorder.

\section{RESULTS}

PREVALENCE After the elimination from the study के of patients who did not suffer from the disease on $\overrightarrow{0}$ 1 January 1958, who did not reside in the counties of Northumberland or Durham on that date, or $\vec{\omega}$ were believed after careful clinical evaluation not to have multiple sclerosis, 1,156 cases remained for analysis. The overall prevalence of established multiple $i$ sclerosis in the two counties was $50 \cdot 1$ per 100,000 population. This must clearly be regarded as minimal figure. We cannot estimate the number of $\infty$ established cases which escaped our case-findirfo 응 methods, but we believe that this figure would almost certainly outweigh the instances in which we hase diagnosed multiple sclerosis in patients affected bo some other disorder. Another obvious source of क underestimation is the interval which elapses almost every case between initial symptoms, which in themselves may postdate unequivocal physical signs of a structural lesion, and definitive diagnosis. The population undoubtedly contains cases in which the disease is as yet unrecognized.

COMPARISON OF CASE GROUPS The three case groups are compared in Table II. Group A consists of 636 patients referred by practitioners who were intensively studied for clinical as well as epidemiological purposes. Group B comprises 118 patients referred by physicians who were less thoroughly studied so as to establish a diagnosis for epidemiological purposes only. Group C consists of 402 cases extracted from hospital records.

Of the total number of cases, $55 \%$ came from the intensive clinical cadre, $10 \%$ from the less carefully studied group, and $35 \%$ from hospital records. An appreciable proportion of the patients in whom $\frac{\text { S }}{3}$ the diagnosis of multiple sclerosis had been made before 1 January 1958 were not reported by their general practitioners, although in fact every case $N$ was on the National Health Service list of some practitioner: the service covers more than $98 \%$ of the total population of the area. The failure of $\omega$ 
TABLE II

COMPARISON OF STUDY GROUPS OF CASES OF MULTIPLE SCLEROSIS BY SEX, AGE, DURATION OF DISEASE, AND GEOGRAPHICAL LOCATION

\begin{tabular}{lll}
$\begin{array}{l}\text { Group A } \\
\text { (Physicians, } \\
\text { Intensive } \\
\text { Study) }\end{array}$ & $\begin{array}{l}\text { Group B } B^{2} \\
\text { (Physicians) }\end{array}$ & $\begin{array}{l}\text { Group } C^{3} \\
\text { (Hospitals) }\end{array}$ \\
\hline
\end{tabular}

\begin{tabular}{|c|c|c|c|}
\hline $\begin{array}{l}\text { Total number of cases } \\
\text { in group } \\
\text { Percentage of all cases } \\
\text { studied }\end{array}$ & $\begin{array}{l}636 \\
55 \cdot 0\end{array}$ & $\begin{array}{l}118 \\
10 \cdot 2\end{array}$ & $\begin{array}{l}402 \\
34 \cdot 8\end{array}$ \\
\hline $\begin{array}{l}\text { Sex of cases } \\
\text { Male ( } \% \text { total }) \\
\text { Female }(\% \text { total })\end{array}$ & $\begin{array}{l}41 \cdot 7 \\
58 \cdot 3\end{array}$ & $\begin{array}{l}39 \cdot 8 \\
60 \cdot 2\end{array}$ & $\begin{array}{l}40 \cdot 5 \\
59 \cdot 5\end{array}$ \\
\hline $\begin{array}{l}\text { Mean age at onset (yr.) } \\
\text { Mean age on prevalence } \\
\text { day (yr.) } \\
\text { Mean duration of disease } \\
\text { (yr.) }\end{array}$ & $\begin{array}{l}34 \cdot 5 \\
44 \cdot 0 \\
11 \cdot 6\end{array}$ & $\begin{array}{l}37 \cdot 6 \\
45 \cdot 0 \\
10 \cdot 0\end{array}$ & $\begin{array}{r}37 \cdot 3 \\
43 \cdot 7 \\
8 \cdot 0\end{array}$ \\
\hline $\begin{array}{l}\text { Geographical distribution } \\
\text { Newcastle }(\%) \\
\text { Other urban }(\%) \\
\text { Rural }(\%)\end{array}$ & $\begin{array}{l}20 \cdot 3 \\
63 \cdot 5 \\
16 \cdot 2\end{array}$ & $\begin{array}{l}13 \cdot 5 \\
63 \cdot 5 \\
23 \cdot 0\end{array}$ & $\begin{array}{l}15 \cdot 9 \\
66 \cdot 1 \\
18 \cdot 0\end{array}$ \\
\hline
\end{tabular}

'Group A Physicians' referral cases individually studied at length. ${ }^{2}$ Group B Physicians' referral cases less thoroughly studied; some data by mail or sources other than patient.

${ }^{3}$ Group C Cases from hospital records.

practitioners to report many cases traced in other ways is a commentary on the way in which these patients may escape the attention of the doctor, who has so little to offer them in the way of effective therapy.

The three groups were remarkably similar in their sex ratios, $41 \cdot 1 \%$ of all patients being male and $58.9 \%$ female. The mean age on prevalence day was about 44 years for the total, but the mean duration of the disease varied among the three groups. Those in the first group of cases reported had suffered from the disease for a mean period of 11.6 years, those in group B for 10 years, and those traced from hospital records for eight years. It seems likely that patients who have had the disease for a longer period are generally more disabled and remain more readily in contact with their general practitioners. The geographical distribution of cases in the three groups was similar, though a higher proportion of patients in the first group came from Newcastle.

DiAgNOSTIC CATEgORIES In Table III all cases studied are divided into probable, latent, and possible categories. The cases allotted to the probable category represented $77.7 \%$ of the total, while $5.2 \%$ were latent and $17 \cdot 1 \%$ possible. The proportions of male and of female cases coming within each of the three categories were not essentially different, though a slightly higher proportion of females fell
TABLE III

PROBABLE, LATENT, AND POSSIBLE CASES OF MULTIPLE SCLEROSIS BY AGE, DURATION OF DISEASE, GEOGRAPHICAL LOCATION, AND SEX

\begin{tabular}{lccc} 
& \multicolumn{3}{c}{ Diagnostic Category } \\
\cline { 2 - 4 } & Probable & Latent & Possible \\
\hline Total (\%) & $77 \cdot 7$ & $5 \cdot 2$ & $17 \cdot 1$ \\
Sex of cases & & & \\
Male (\%) & $74 \cdot 9$ & $4 \cdot 4$ & $20 \cdot 8$ \\
Female (\%) & $79 \cdot 7$ & $5 \cdot 7$ & $14 \cdot 6$ \\
Mean age at onset (yr.) & $35 \cdot 5$ & $32 \cdot 8$ & $40 \cdot 8$ \\
Mean age prevalence day (yr.) & $43 \cdot 5$ & $37 \cdot 2$ & $49 \cdot 3$ \\
Mean duration of disease (yr.) & $10 \cdot 8$ & $7 \cdot 1$ & $9 \cdot 2$ \\
Geographical distribution & & & \\
Newcastle (\%) & $74 \cdot 2$ & $10 \cdot 1$ & $15 \cdot 7$ \\
Other urban (\%) & $79 \cdot 5$ & $4 \cdot 1$ & $16 \cdot 4$ \\
Rural (\%) & $72 \cdot 5$ & $7 \cdot 2$ & $20 \cdot 3$
\end{tabular}

in the probable and a smaller proportion in the possible category. The patients diagnosed as having latent disease were younger as a group on prevalence day, and had suffered from the disease for a mean period of only $7 \cdot 1$ years, which may account in part for the absence of disablement at the time of evaluation. The average age of patients in the probable group on prevalence day was 43.5 years with a mean age at onset of 35.5 years, and these had suffered from the disease for a mean period of 10.8 years before prevalence day. The duration of the illness in the possible group was slightly shorter $(9 \cdot 2$ years) but as a group these patients were older, with an average age of 49.3 years on prevalence day. Figure 2 presents the age distribution of cases in each diagnostic group. The fact that the patients in the possible group were older may indicate reluctance of neurologists to diagnose multiple sclerosis firmly in older patients, and also a tendency of the disease to atypical presentation under these circumstances.

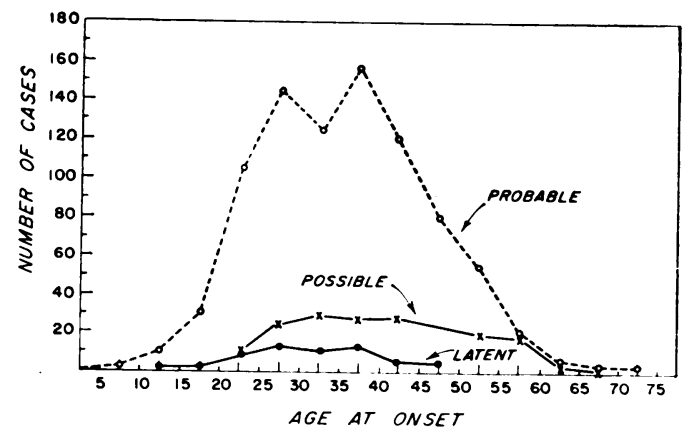

FIG. 2. Age distribution at onset of patients in Northumberland and Durham known to have multiple sclerosis on prevalence day, 1 January 1958, by diagnostic category. 
TABLE IV

YEAR OF BIRTH VERSUS YEAR OF ONSET BY FIVE-YEAR PERIODS IN CASES OF MULTIPLE SCLEROSIS

Year of Birth Year of Onset

\begin{tabular}{lllllllllllll}
\hline 1910 & 15 & 20 & 25 & 30 & 35 & 40 & 45 & 50 & 55 & Unknown \\
1914 & 19 & 24 & 29 & 34 & 39 & 44 & 49 & 54 & 59 &
\end{tabular}

\begin{tabular}{|c|c|c|c|c|c|c|c|c|c|c|c|c|}
\hline $1880-84$ & 1 & 1 & & & 1 & & & 1 & & & & 4 \\
\hline $1885-89$ & 1 & & 2 & & 1 & 2 & 2 & & 1 & & 1 & 10 \\
\hline $1890-94$ & & & 1 & 9 & 4 & 4 & 4 & 2 & 2 & 2 & 1 & 29 \\
\hline $1895-99$ & 1 & 1 & 3 & 1 & 6 & 13 & 15 & 12 & 19 & 8 & 0 & 79 \\
\hline $1900-04$ & & 1 & 6 & 9 & 9 & 15 & 21 & 32 & 37 & 18 & 3 & 151 \\
\hline $1905-09$ & & 1 & 3 & 9 & 11 & 20 & 23 & 32 & 37 & 19 & 6 & 161 \\
\hline $1910-14$ & & & 1 & 1 & 7 & 20 & 21 & 50 & 51 & 22 & 5 & 178 \\
\hline 1915-19 & & 1 & & 1 & 5 & 11 & 30 & 30 & 52 & 33 & 4 & 167 \\
\hline $1920-24$ & & & & 1 & & 2 & 18 & 34 & 41 & 41 & 1 & 138 \\
\hline $1925-29$ & & & & & 1 & 2 & 8 & 21 & 44 & 42 & 5 & 123 \\
\hline $1930-34$ & & & & & & & 4 & 4 & 26 & 32 & 1 & 67 \\
\hline $1935-39$ & & & & & & & & 3 & 7 & 21 & 1 & 32 \\
\hline $1940-45$ & & & & & & & & & 1 & 1 & 0 & 2 \\
\hline Unknown & & & & & & & & & & 3 & 12 & 15 \\
\hline Total & 3 & 5 & 16 & 31 & 45 & 89 & 146 & 221 & 318 & 242 & 40 & 1,156 \\
\hline
\end{tabular}

AGE Table IV compares the year of birth and the y ear of onset by five-yearperiods in the 1,156 patients in this study. The age distribution at onset by sex is given in Figure 3. The distribution of ages by fiveyear periods in Table $\mathrm{V}$ indicates a mean age at onset of $36 \cdot 3$ years. This figure is somewhat higher than that found in certain other studies, although when the data for Northumberland and Durham are tabulated in the fashion used by McAlpine the mean age for this series becomes 33.0 years as compared with 31.0 years for the Middlesex Hospital group, 31.7 years for the Adams and Sutherland series, and 25.9 years for the Müller series (McAlpine, Compston, and Lumsden, 1955). The older age at onset in Northumberland and Durham may possibly represent a tendency to delayed diagnosis in the area. On the other hand it might be taken to indicate a less than average reluctance to diagnose multiple sclerosis in an elderly patient if the clinical criteria are fulfilled.

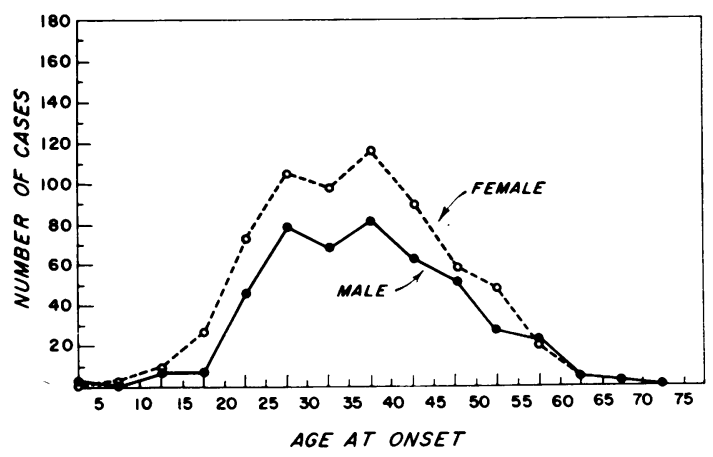

FIG. 3. Age distribution at onset of cases of multiple sclerosis in Northumberland and Durham on 1 January 1958 by sex.

TABLE V

DISTRIBUTION OF AGES AT ONSET BY FIVE-YEAR PERIODS

\begin{tabular}{|c|c|c|}
\hline Ages & Cases & $\%$ \\
\hline $0-4$ & 1 & 0.1 \\
\hline $5-9$ & 2 & $0 \cdot 2$ \\
\hline $10-14$ & 13 & $1 \cdot 1$ \\
\hline $15-19$ & 33 & 2.9 \\
\hline $20-24$ & 120 & 10.4 \\
\hline $25-29$ & 184 & 15.9 \\
\hline $30-34$ & 166 & $14 \cdot 4$ \\
\hline $35-39$ & 199 & $17 \cdot 2$ \\
\hline $40-44$ & 154 & $13 \cdot 3$ \\
\hline $45-49$ & 111 & 9.6 \\
\hline $50-54$ & 75 & 6.5 \\
\hline $55-59$ & 41 & $3 \cdot 5$ \\
\hline $60-64$ & 10 & 0.9 \\
\hline $65-69$ & 4 & 0.3 \\
\hline Unknown & 43 & $3 \cdot 7$ \\
\hline Total &, 156 & $100 \cdot 0$ \\
\hline
\end{tabular}

Mean age at onset $=36 \cdot 3$

The cases in this study are plotted in Fig. 4 by year of birth and in Fig. 5 by year of onset. It does not appear that there is any conspicuous cyclical or epidemic pattern either by year of birth or by year of onset in this series of patients.

GEOGRAPHICAL DISTRIBUTION Of the 1,156 cases, 1,006 developed the disease while resident in Northumberland and Durham, 79 in other counties of the United Kingdom, and 10 outside the United Kingdom. In 61 cases the place of onset was unknown or the time of onset indefinite (Table VI). When the two counties are compared with one another, the proportions of male and female cases were essentially the same. The distribution of probable, possible, and latent cases was remarkably similar, $64.7 \%$ of the cases in Northumberland being counted as probable and $68.8 \%$ in Durham. The distribution by years of onset was essentially similar 


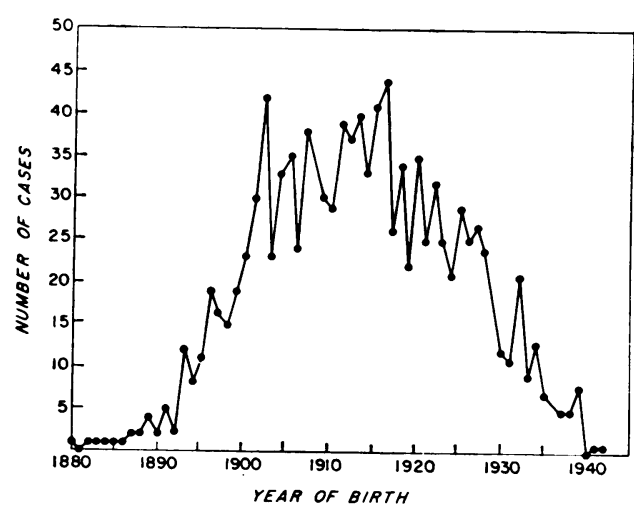

FIG. 4. Years of birth of patients in Northumberland and Durham known to have multiple sclerosis on prevalence day, 1 January 1958.

in the two counties, with no predominance of cases in any particular period in one county that was not reflected in the same period of onset in the other. In each five-year period 52.7 to $55.6 \%$ of cases developed the disease in Durham, 28.8 to $36.8 \%$ in Northumberland.

All cases were categorized both by place of onset and by place of birth. These two tabulations are shown separately by county and by urban and rural areas in Table VII and by sub-districts within the counties in Table VIII.

The rates shown in Table VII by county of onset show a reasonable consistency, with a rate of $48 \cdot 2$ per 100,000 for Northumberland and $41 \cdot 1$ per 100,000 for Durham, based on 1,006 cases with onset in these two counties. The rates by place of birth for the two counties are even closer, 33.1 per 100,000 for Durham and $37 \cdot 7$ per 100,000 for Northumberland. It should be pointed out that the overall prevalence rate for the study is $50 \cdot 1$ per 100,000 when the entire 1,156 cases are analysed together.

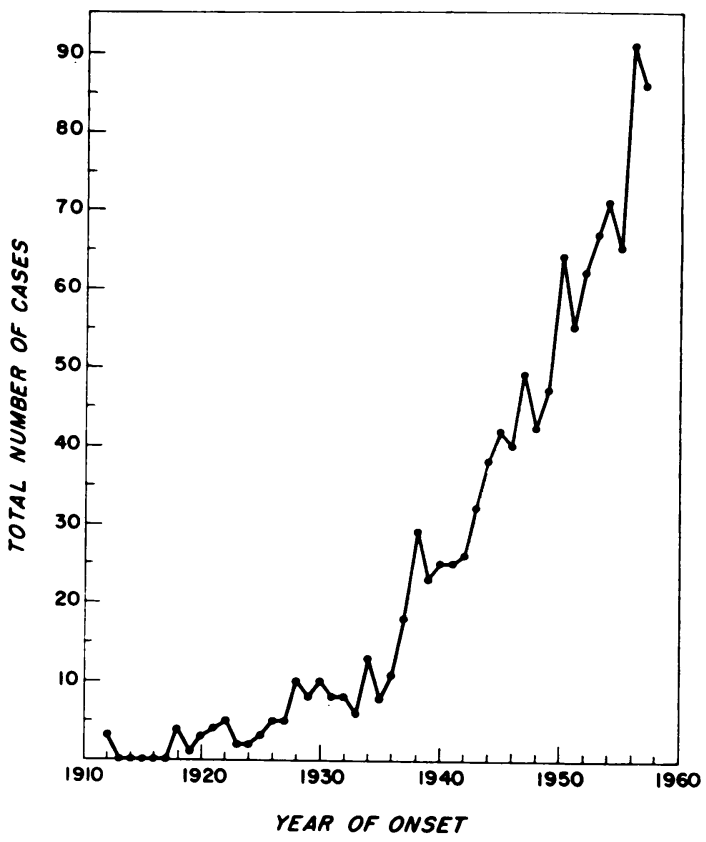

FIG. 5. Years of onset of patients in Northumberland and Durham known to have multiple sclerosis on prevalence day, 1 January 1958.

TABLE VI

DISTRIBUTION OF MULTIPLE SCLEROSIS CASES BY SEX AND COUNTY OR PLACE OF ONSET

\begin{tabular}{lrcc} 
& Cases & $\%$ Male & $\%$ Female \\
\hline Northumberland & 391 & $38 \cdot 9$ & $61 \cdot 1$ \\
Durham & 615 & $42 \cdot 1$ & $57 \cdot 9$ \\
Other counties & 79 & $50 \cdot 1$ & $49 \cdot 9$ \\
Outside Britain & 10 & $60 \cdot 0$ & $40 \cdot 0$ \\
Unknown place or indefinite & 61 & $27 \cdot 9$ & $72 \cdot 1$ \\
onset & 61 & $41 \cdot 1$ & 58.9 \\
Total & 1,156 & &
\end{tabular}

TABLE VII

DISTRIBUTION OF MULTIPLE SCLEROSIS CASES BY COUNTY OF ONSET AND COUNTY OF BIRTH, URBAN AND RURAL

\begin{tabular}{|c|c|c|c|c|c|}
\hline \multirow[t]{2}{*}{ District } & \multirow[t]{2}{*}{1958 Population (est.) ${ }^{1}$} & \multicolumn{2}{|c|}{ By Place of Onset } & \multicolumn{2}{|c|}{ By Place of Birth } \\
\hline & & Cases & Rate per 100,000 & Cases & Rate per 100,000 \\
\hline $\begin{array}{l}\text { Northumberland } \\
\text { Urban } \\
\text { Rural }\end{array}$ & $\begin{array}{l}811,400 \\
682,770 \\
128,630\end{array}$ & $\begin{array}{r}391 \\
333 \\
58\end{array}$ & $\begin{array}{l}48 \cdot 2 \\
48 \cdot 8 \\
45 \cdot 1\end{array}$ & $\begin{array}{r}306 \\
252 \\
54\end{array}$ & $\begin{array}{l}37 \cdot 7 \\
36 \cdot 9 \\
42 \cdot 0\end{array}$ \\
\hline $\begin{array}{l}\text { Durham } \\
\text { Urban } \\
\text { Rural }\end{array}$ & $\begin{array}{r}1,497,000 \\
1,191,430 \\
305,570\end{array}$ & $\begin{array}{l}615 \\
499 \\
116\end{array}$ & $\begin{array}{l}41 \cdot 1 \\
41 \cdot 9 \\
38 \cdot 0\end{array}$ & $\begin{array}{l}496 \\
396 \\
100\end{array}$ & $\begin{array}{l}33 \cdot 1 \\
33 \cdot 2 \\
32 \cdot 7\end{array}$ \\
\hline $\begin{array}{l}\text { Total both counties } \\
\text { Total urban } \\
\text { Total rural }\end{array}$ & $\begin{array}{r}2,308,400 \\
1,874,200 \\
434,200\end{array}$ & $\begin{array}{r}1,006 \\
832 \\
174\end{array}$ & $\begin{array}{l}43 \cdot 6 \\
44 \cdot 4 \\
40 \cdot 1\end{array}$ & $\begin{array}{l}802 \\
648 \\
154\end{array}$ & $\begin{array}{l}34 \cdot 7 \\
34 \cdot 6 \\
35 \cdot 5\end{array}$ \\
\hline
\end{tabular}

${ }^{1}$ Registrar General's estimate of population 1958 
TABLE VIII

DISTRIBUTION AND RATES OF MULTIPLE SCLEROSIS CASES BY PLACE OF ONSET AND PLACE OF BIRTH

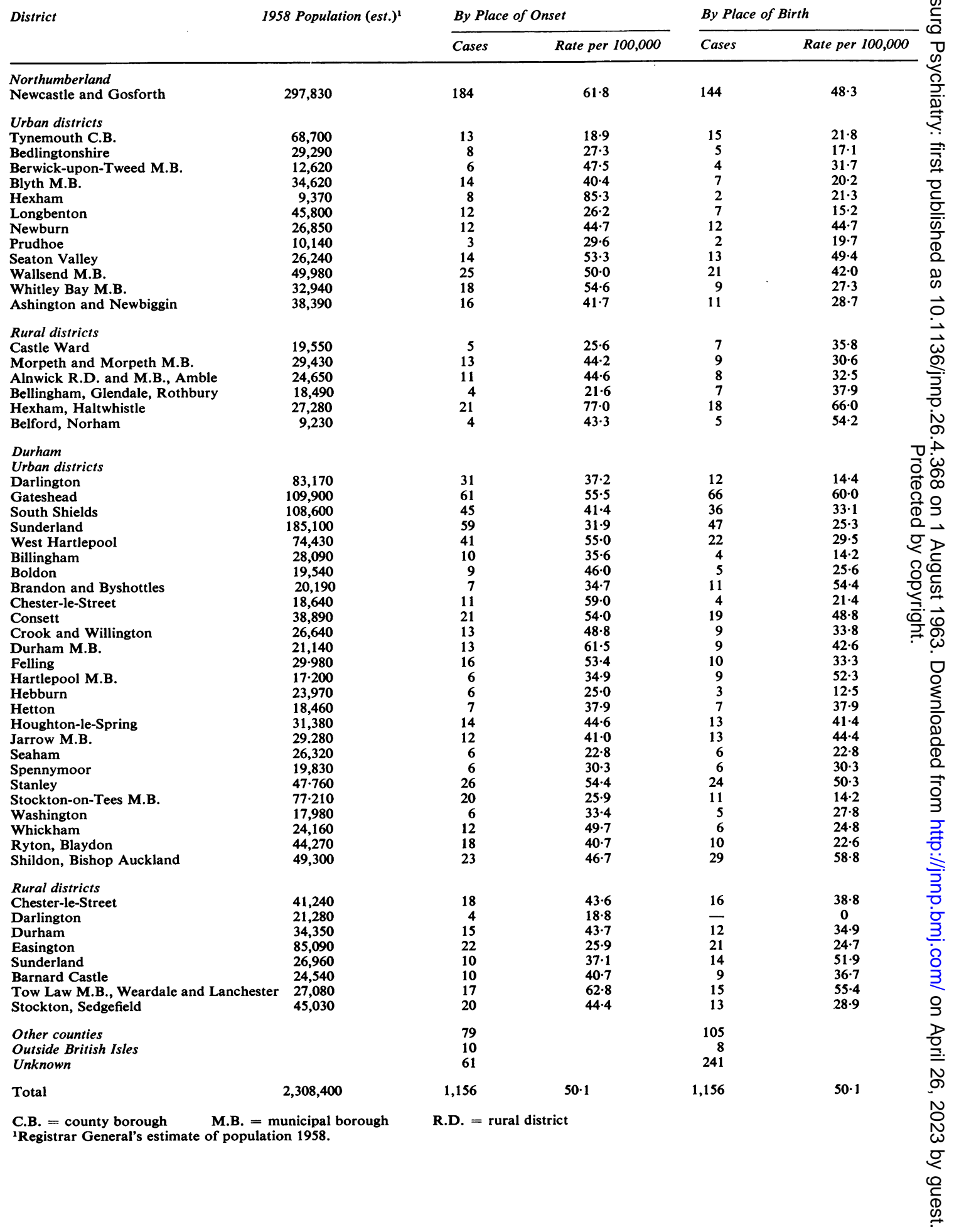


Cases were assigned by their place of onset and also by their place of birth to 53 districts within the two counties. The districts are listed as urban or rural according to the Registrar General's classification. An attempt was made to group the districts into units approaching 15,000 population for statistical purposes, where two adjacent small districts had essentially the same characteristics and degree of urban development. It was not possible to do this where an area was dissimilar in its nature from those adjacent to it, and therefore four districts fall below the 15,000 population limit. The rates of multiple sclerosis cases by place of onset and by place of birth for each of the 53 districts are given in Table VIII.

In the few studies in which small subdivisions of a surveyed area have been studied, it has been suggested that wide variations occur in the rate of multiple sclerosis in immediately adjacent areas (Georgi and Hall, 1960; Bammer and Schaltenbrand, 1960). This impression may appear to be borne out by initial perusal of the wide range in rates in the $\mathbf{5 3}$ districts listed in Table VIII. However, if the distribution of these rates is compared with the expected distribution for the occurrence of small numbers of cases in large populations (Poisson distribution) as indicated in Table IX, the prevalence rates by place of onset fall remarkably close to the expected distribution and are not significantly different from it. Despite the wide discrepancies in the actual rates, these rates are those which would be expected statistically.

A somewhat wider spread of prevalence rates is found when the rates are compared for places of birth in the various districts. This distribution is significantly different from the expected. Several explanations may be offered. The data by place of birth are probably less accurate and are less complete than the data by place of onset. Many persons born in the area who had onset years later have already moved out of the district so that the data are incomplete. On the other hand, it should be mentioned that place of birth may be more significant than place of onset in the distribution of multiple sclerosis. Acheson (1961) noted a regular geographical shift with latitude when using the birthplace of veterans in the United States. Our own studies of familial and conjugal multiple sclerosis point to acquisition of multiple sclerosis early in life, possibly about the age of 14 (Schapira, Poskanzer, and Miller, 1963). It is more likely, however, that the data for onset by place of birth are not sufficiently complete. This form of statistical analysis is relevant to any study where an apparently wide diversity in prevalence rates may reflect nothing more than the small numbers of cases in large populations.

When all urban districts, as indicated by the Registrar General's Report, are compared with all rural districts by place of onset or by place of birth, the rates in the two types of districts are remarkably comparable (Table VII).

LIFE EXPECTANCY An estimate of the duration of the disease was derived from the study of the period from onset to prevalence day as calculated for all 1,156 patients. Assuming that there is no change in the basic pattern of the disease its average duration may be calculated as twice the average period from onset to prevalence day. Calculated in this way, the mean duration of multiple sclerosis in our series was 19.3 years (19.1 years for males, 19.5 years for females).

By using the 1956-1958 life tables for England and Wales as applied to populations of men and women with the same age distribution as the cases in the study, it was calculated that the mean life expectancy of a group of men with the age distribution of the males in our series would be 28.6 years, the expectation in a group of women 33.9 years. As mentioned above, the duration of the disease in men had been calculated from this study as $19 \cdot 1$ years, in women as 19.5 years. From these data it is possible to make a rough estimate of the reduction in life expectancy which occurs as a result of multiple sclerosis. Our data would indicate that in men normal life expectancy is reduced by $9 \cdot 5$ years and in women

TABLE IX

DISTRIBUTION OF PREVALENCE RATES

Total

Patients located by place of onset

Number of standard deviations from mean

Number of districts

Expected distribution

$>-2$

$1 \cdot 2$

$7^{-2}$ to -1

$7 \cdot 2$

$\frac{-1}{16}$ to 0

$18 \cdot 1$

0 to 1

17
$18 \cdot 1$

1 to 2

$7 \cdot 2$

$>2$

$1 \cdot 2$

53

53

Patients located by place of birth

Number of districts

Expected distribution

$\begin{array}{ll}4 & 9 \\ 1 \cdot 2 & 7 \cdot 2\end{array}$

Chi square $=16.4$ for 5 D.F. (significantly different at 0.01 level)
17
$18 \cdot 1$
11

$18 \cdot 1$
8
$7 \cdot 2$

$7 \cdot 2$ 
by 14.4 years. The difference probably reflects the greater life expectancy of women in any population, which is presumably negated by the occurrence of multiple sclerosis.

\section{SUMMARY}

A survey was made of established cases of multiple sclerosis in the counties of Northumberland and Durham (population 2,308,400) based on reports of all known cases by general practitioners $(88.6 \%$ reporting) and a search of the records of the 29 hospitals in the area. In all 1,156 patients were found who resided in the two counties and suffered from the disease on prevalence day (1 January 1958). The overall prevalence rate was $50 \cdot 1$ per 100,000 .

Cases were divided into probable, latent, and possible groups, with $77.7 \%$ in the first group, $5.2 \%$ in the second, and $17 \cdot 1 \%$ in the third. The overall mean age at onset was $36 \cdot 3$ years. No conspicuous cyclical or epidemiological pattern was found when the cases were analysed either by year of onset or by year of birth.

When rates were compared for urban versus rural distribution no difference was found in either county. Cases were assigned to 53 districts within the counties, both by year of onset and year of birth. The rates, though they varied markedly, assumed a Poisson distribution and indicated that the wide diversity in prevalence rates found here, and in other studies of small population divisions, may reflect nothing more than the small numbers of cases in large populations.
An estimate of mean life expectancy for a population with the same age distribution as these patients, when compared with a computed duration of the disease, indicated that life expectancy is reduced in men by 9.5 years and in women by 14.4 years as a result of having multiple sclerosis.

The authors wish to thank the Board of Governors of The Royal Victoria Infirmary, the Multiple Sclerosis Societies of Great Britain and the United States, the $\Rightarrow$ North-East Multiple Sclerosis Trust, and the Medical $\stackrel{\oplus}{\stackrel{D}{+}}$ Foundation Inc. of Boston for their generous support of these investigations.

\section{REFERENCES}

Acheson, E. D. (1961). Brit. J. prev.soc. Med., 15, 118

- , and Bachrach, C. A. (1960). Amer. J. Hyg., 72, 88

and Wright, F. M. (1960). Acta psychiat. neurol scand. 35, suppl., 147 , p. 132

Allison, R. S. (1931). Brain, 53, 391.

_, and Millar, J. H. D. (1954). Ulster med. J., 23, suppl., 2, p. 5.

Alter, M., Allison, R. S., Talbert, O. R., and Kurland, L. T. (1960). Wld. Neurol., 1, 55.

Bammer, H., and Schaltenbrand, G. (1960). Acta psychiat. neurol. is scand., 35, suppl., 147, p. 57.

Chiavacci, L. V., Hoff, H., and Polvan, N. (1950). Arch. NeurotD Psychiat. (Chic.), 64, 546.

Georgi, F., and Hall, P. (1960). Acta psychiat. neurol. scand., 3ร్ట suppl., 147, p. 75.

Hyllested, K. (1956). Disseminated Sclerosis in Denmark, Prevalen and Geographic Distribution. Jorgensen, Copenhagen.

Ipsen, J. Jr. (1950). Arch. Neurol. Psychiat. (Chic.), 64, 631.

Limburg, C. C. (1950). Res. Publ. Ass. Res. nerv. Dis., 28, 15.

MacLean, A. R., Berkson, J., Woltman, H. W., and Schionneman, (1950). Ibid., 28, 25

McAlpine, D., Compston, N. D., and Lumsden, C. E. (1955). Multipte Sclerosis. Livingstone, Edinburgh and London.

Schapira, K., Poskanzer, D. C., and Miller, H. (1963). Brain, in pres?़् क् Sutherland ,J. M. (1956). Ibid., 79, 635. 